\title{
BMJ Open Factors affecting utilisation of traditional Korean medical services by privately insured persons: a retrospective study using Korean Health Panel Survey (KHPS)
}

Boyoung Jung (D) , ${ }^{1}$ Juchul Kim, ${ }^{2}$ In-Hyuk Ha (D) , ${ }^{1}$ Jinho Lee ${ }^{3}$

To cite: Jung B, Kim J, Ha I$\mathrm{H}$, et al. Factors affecting utilisation of traditional Korean medical services by privately insured persons: a retrospective study using Korean Health Panel Survey (KHPS). BMJ Open 2020;10:e033159. doi:10.1136/ bmjopen-2019-033159

- Prepublication history and additional material for this paper are available online. To view these files, please visit the journal online (http://dx.doi. org/10.1136/bmjopen-2019033159).

Received 23 July 2019 Revised 03 December 2019 Accepted 10 December 2019

Check for updates

(c) Author(s) (or their employer(s)) 2020. Re-use permitted under CC BY-NC. No commercial re-use. See rights and permissions. Published by BMJ.

${ }^{1}$ Jaseng Spine and Joint Research Institute, Jaseng Medical Foundation, Seoul, Republic of Korea

${ }^{2}$ Research Department, Research Institute of Korean Medicine Policy, Seoul, Heojunro, Gangseo-gu, Republic of Korea

${ }^{3}$ Jaseng Hospital of Korean Medicine, Seoul, Gangnamdaero, Gangnam-gu, Republic of Korea

Correspondence to

Boyoung Jung;

happiness630@hanmail.net

\section{ABSTRACT}

Objective This study aimed to use the Korean Health Panel Survey (KHPS) data to identify the key factors that influence decisions regarding the use of traditional Korean medicine (TKM) by privately insured persons.

Design A retrospective study on episodic KHPS data from 2009 to 2013.

Setting Nationwide-based survey using the KHPS data. Participants The study included outpatients aged $\geq 20$ years who had used private medical insurance at least once during the 5 years of the survey. After excluding cases where TKM was not used and those with missing values, this study ultimately included 1874 patients. Primary and secondary outcome measures The main dependent variable was TKM utilisation (number of outpatient visits and outpatient costs of TKM). We used multiple linear regression analysis to identify determinants of TKM while controlling for clustered errors.

Results Approximately 6.1\% (1874) of all doctor visits (30 982) were characterised as TKM services. For therapeutic purposes, TKM visits increased despite not being guaranteed in private health insurance (coefficient=3.0, $p=0.045$ ) and TKM outpatient costs decreased (coefficient $=-0.3, p=0.001$ ). Women used more therapeutic TKM services than men (coefficient=2.8, $p<0.001$ ). Older patient groups used more therapeutic TKM services than younger patient groups (coefficient $=11.5, p=0.012$ ), but paid less on outpatient costs than younger groups (coefficient $=-1.0$, $p=0.001$ ). For preventive services, sex and age were not statistically significant factors. Regardless of the purpose of the visit, the more chronic diseases, the more people who have previously experienced TKM service use more TKM services $(p<0.001)$.

Conclusions Despite a policy to reduce services that are not guaranteed by private health insurance, the increase in the number of outpatient visits for uncovered therapeutic TKM services implies a high public need for TKM in Korea.

\section{INTRODUCTION}

Korea has achieved universal health coverage through the mandatory National Health Insurance (NHI). However, as of 2013, the public sector accounts for only $55.9 \%$ of the
Strengths and limitations of this study

- This study analysed the use of traditional Korean medicine services by privately insured persons based on the Korean Health Panel Survey (KHPS) data.

- The results of the study clarify the various patterns of consumption behaviours as well as supply patterns of private healthcare services for private health insurance subscribers.

- This study is unique in that it compares medical service usage, including uncovered services, by privately insured persons in Korea.

- The study findings cannot be generalised outside of Korea due to differences in cultural background and reimbursement systems between countries.

- The findings are subject to recall bias, and various covariates for utilisation of outpatient services could not be controlled because KHPS data are from patient questionnaires rather than medical records.

total health expenditure, which is well below the average of $72.7 \%$ for Organisation for Economic Co-operation and Development (OECD) countries. ${ }^{1}$ In 2013, public medical expenditure accounted for $55.9 \%$ (54.9 trillion won) of the total medical expenses, while civilian medical expenses accounted for the remaining $44.1 \%$ (43.3 trillion won). In that same year, medical expenses in Korea totalled 98.3 trillion won, and the overall medical expenditure was $6.9 \%$ of the gross domestic product, which is $2.0 \%$ lower than the OECD average of $8.9 \% .^{1}$ Notably, the amount spent on 'personal medical expenses', excluding healthcare expenses for prevention, public health projects and health administration, was 90.7 trillion won; this corresponds to $92.3 \%$ of the total medical expenses in Korea. The universal coverage of Korea's healthcare system has contributed to a marked improvement in health conditions, while achieving 
one of the lowest levels of public spending among the OECD countries through high patient copayments and limited coverage of public health insurance. ${ }^{2}$ The NHI includes 'covered services' and 'uncovered services'; the latter include services not guaranteed by the NHI and for which the patient must pay $100 \%$ of the treatment costs. ${ }^{3}$ Health promotions for preventive rather than for therapeutic purposes are considered 'uncovered services' and are excluded from the NHI. Among these types of services, the field of traditional Korean medicine (TKM) is often excluded from the covered medical services due to health insurance conditions. As there are relatively fewer examinations and surgeries in TKM compared with Western medicine, the proportion of uncovered services is relatively high. Specifically, as of 2016, there were 5676 covered services and 614 uncovered services in Western medicine compared with 240 covered services and 16 uncovered services in TKM. ${ }^{4}$

The rate of NHI coverage over the past decade has been $63.2 \%$, indicating that the government has increased the burden of medical expenses. Moreover, the government has introduced and expanded the private health insurance (PHI) system, which complements public system coverage by cost-sharing. ${ }^{5}$ In 2017, the Korean government announced measures to strengthen health insurance coverage, which included the slogan of solving medical expenses with one health insurance. This strategy was chosen because Koreans tend not to buy private insurance due to slightly higher health insurance premiums. Thus, the NHI is best equipped to solve the problems and burden of medical expenses. More than $77 \%$ of households purchased at least one PHI policy in $2009,{ }^{6}$ and more than $64 \%$ of individuals purchased at least one PHI policy in 2010. ${ }^{7}$

Recently, in Korea and around the world, interest and research in complementary medicine approaches have been increasing. ${ }^{69}$ The Korean medical system is characterised by the simultaneous presence and usage of Western medicine and traditional medicine systems. ${ }^{7}$ Although the efficacy of TKM has been validated by many studies, ${ }^{10-12}$ its use in Korea accounts for a small percentage of the total healthcare services and public interest in TKM is declining. According to the results of a survey on medical use and herbal medicine consumption in $2014,{ }^{13}$ the biggest obstacle to utilisation of medical care in Korea was the burden of cost $(46.5 \%)$, which was considered the first priority in the improvement of use of TKM. In 2014, Korea's health insurance coverage rates were $53.2 \%$ for Korean traditional clinics and $36.7 \%$ for Korean traditional hospitals, which are lower than the coverage rates for Western medicine clinics. In Korea, the role of PHI, which provides health insurance with a low coverage and burden of cost, is relatively more important in TKM institutions than in Western hospitals.

The initial model of PHI provided compensation for uncovered expenses, largely to allow treatment in TKM institutions through various specialised methods. However, TKM was excluded from the full implementation of the standardisation plan for PHI in October 2009. This exclusion was based on the assumption that TKM is more likely to be used for preventive rather than therapeutic purposes, and that moral hazards are likely to occur. The purpose of this study was to identify factors that influence the utilisation of TKM, such as demographic and socioeconomic characteristics, and the effects of the policy that reduced the compensation scope of PHI based on the reasons for visiting a medical institution (therapeutic or preventive purpose).

\section{METHODS}

\section{Database}

The Korea Institute for Health and Social Affairs and the National Health Insurance Corporation (NHIS) have formed a consortium to jointly conduct a nationwide Korean Health Panel Survey (KHPS) V.1.2.2 to obtain basic data regarding healthcare utilisation, health expenditure level and health-related behaviours. ${ }^{14}$ The KHPS has been conducted annually since 2008. However, the database from 2008 was excluded because it did not include data for individual health-related behavioural factors (smoking, drinking, exercise, obesity and so on) assessed in our study.

\section{Patient and public involvement}

We used KHPS healthcare data collected from 2009 to 2013 for this retrospective study. The KHPS data include information on each episode of healthcare utilisation and expenditure, as well as the person's PHI status (eg, number of contracts, monthly premium payments and reimbursements). These data alleviate the problems of recall bias associated with the use of housekeeping books or receipts from healthcare expenditures. We also excluded individuals younger than 20 years, as we suspected that individuals in this age group depended on their parents' health insurance. ${ }^{15}$ In Korea, hospitalisation and surgery are decided by the medical service provider (doctor), rather than the patient, following diagnosis of the patient and judgement regarding hospitalisation and operation. Additionally, emergency medical services are most often used for sudden health problems, regardless of whether the patients have PHI.

Therefore, our final study population consisted of outpatients aged $\geq 20$ years who had used private medical insurance at least once during the 5 years of the survey. After excluding cases where TKM was not used and those with missing values, our study ultimately included 1874 patients (figure 1).

\section{Outcomes and other variables}

The dependent variables were the total number of outpatient visits and the total outpatient care expenditure according to the purpose of the visit. In this study, total expenditure was defined as the sum of hospital costs and outpatient prescription drug costs. 
No. of patient who had taken private medical insurance collected from 2009 to 2013

$$
\begin{array}{lll}
- & 2009 & \mathrm{~N}=2,875 \\
- & 2010 & \mathrm{~N}=4,131 \\
- & 2011 & \mathrm{~N}=4,431 \\
- & 2012 & \mathrm{~N}=2,242 \\
- & 2013 & \mathrm{~N}=2.169
\end{array}
$$

No. of patients who had taken private medical insurance collected from 2009 to 2013

$$
\begin{array}{lll}
- & 2009 & \mathrm{~N}=2,728 \\
- & 2010 & \mathrm{~N}=3,902 \\
- & 2011 & \mathrm{~N}=4,219 \\
- & 2012 & \mathrm{~N}=2,156 \\
- & 2013 & \mathrm{~N}=2,094
\end{array}
$$

No. of patients who had taken private medical insurance collected from 2009 to 2013

$$
\begin{aligned}
& \text { - } 2009 \mathrm{~N}=2,409 \\
& \text { - } 2010 \mathrm{~N}=3,369 \\
& \text { - } 2011 \mathrm{~N}=3,622 \\
& \text { - } 2012 \mathrm{~N}=1,819 \\
& \text { - } 2013 \mathrm{~N}=1,824
\end{aligned}
$$

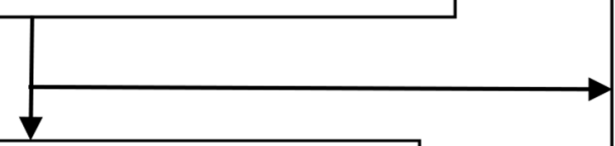

No. of patients who had used Korean traditional medicine from 2009 to 2013

$$
\begin{aligned}
& -\quad 2009 \quad \mathrm{~N}=436 \\
& -\quad 2010 \mathrm{~N}=381 \\
& -\quad 2011 \quad \mathrm{~N}=354 \\
& -\quad 2012 \mathrm{~N}=348 \\
& -\quad 2013 \mathrm{~N}=355
\end{aligned}
$$

Exclude any discrepancies between the personal ID and the household ID

$$
\begin{array}{lll}
- & 2009 & \mathrm{~N}=147 \\
- & 2010 & \mathrm{~N}=229 \\
- & 2011 & \mathrm{~N}=212 \\
- & 2012 & \mathrm{~N}=86 \\
- & 2013 & \mathrm{~N}=75
\end{array}
$$

Excluded patients used only hospitalisation without outpatient visits

$$
\begin{aligned}
& -\quad 2009 \mathrm{~N}=319 \\
& -\quad 2010 \mathrm{~N}=553 \\
& -\quad 2011 \mathrm{~N}=597 \\
& -\quad 2012 \mathrm{~N}=337 \\
& -\quad 2013 \mathrm{~N}=270
\end{aligned}
$$

Excluded cases where there is no use of Korean traditional medicine and individuals whose age was $<20$ years

$$
\begin{array}{lll}
- & 2009 & \mathrm{~N}=1,973 \\
- & 2010 & \mathrm{~N}=2,988 \\
- & 2011 & \mathrm{~N}=3,268 \\
- & 2012 & \mathrm{~N}=1,471 \\
- & 2013 & \mathrm{~N}=1,469
\end{array}
$$


The main independent variable was PHI coverage status (guaranteed/non-guaranteed) of the participants from 2009 to 2012. The initial PHI system model was able to compensate for therapeutic TKM procedures only at institutions with various contracts. However, since October 2009, the private standard medical plans have been enforced and excluded from guaranteed traditional medical service because moral hazard is likely to occur in insured persons who have enrolled in Korean traditional private insurance. ${ }^{16}$ Since Korean traditional medical procedures treat patients by enhancing health from a holistic point of view, it is difficult to clearly distinguish whether a TKM service provides therapy or prevention. Therefore, in this study, each outpatient visit was classified according to the purpose of visit (therapeutic/preventive) to evaluate the effect of the guarantee reduction policy, in which private medical insurance subscribers using traditional medicine were excluded from guaranteed payment.

In KHPS data collection, one question enquires about the reasons for visiting a medical institution for outpatient visits. Based on this question, we created operational definitions for therapeutic, preventive and other purposes, as shown in online supplementary file 1 . The dependent variables were outpatient visits and outpatient cost of TKM. TKM was defined as an outpatient traditional medical service. The independent variable was coverage of PHI (guaranteed, non-guaranteed). This study used a variety of covariates to control for demographic and socioeconomic characteristics and health status. Covariates were classified according to five factors (demographic, socioeconomic, disease-related, health behaviour and health utilisation), as shown in online supplementary file 2. Patient data obtained from the individual databases included demographic and socioeconomic characteristics. Demographic factors included sex, age, marital status and residence. Socioeconomic factors included monthly income, medical insurance type, employment status, type and cost of private insurance, and education. Income was divided into four quartiles of total household income and monthly average living expenses per individual. In case of Medicaid for public health financing, individuals qualified for medical aid if their household income was $<\$ 600$ per month, based on a single household. Medical services for veterans and beneficiaries were provided free of charge by the government. Disease-related factors included disability, the number of chronic diseases and disease diagnosis during a hospital visit. Health behaviour factors included smoking, drinking, exercise and body mass index. Finally, health utilisation factors included the purpose of visit, frequent visits to a hospital and previous experience of Western or Korean medicine. The operational definition of previous experience of Western or Korean medicine was derived using the number of outpatient visits for Korean or Western medicine in the previous year: $1 \mathrm{Q}$ (1 visit per year), $2 \mathrm{Q}$ (2 visits per year), 3Q (3-12 visits per year), 4Q (13-24 visits per year) and $5 \mathrm{Q}$ (25 visits or more per year).
The prevalence of use of medical service type

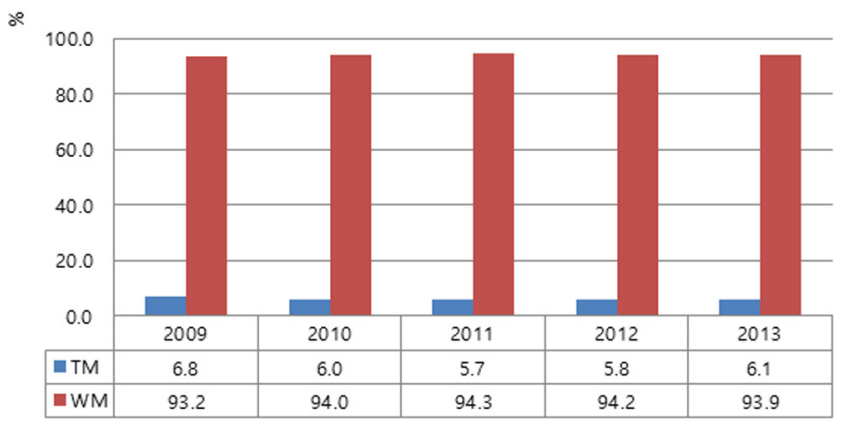

Figure 2 Prevalence of use of Korean traditional medicine (2009-2013). TM, traditional medicine; WM, Western medicine.

\section{Statistical analysis}

We used simple frequencies to describe the characteristics of the episodes on the basis of the type of medical services a patient received. Categorical variables describing the characteristics of the study subjects were presented as frequency and percentage, whereas continuous variables (eg, age, number of medical uses and cost) were presented as mean $\pm \mathrm{SD}$. We converted the costs into 2018 US dollars (US $\$ 1=1133.5$ Korean won as of 5 October 2018). Because this distribution was skewed to the left, ${ }^{17} \mathrm{a}$ $\log$ conversion was performed for cost. ${ }^{18}$

Next, multiple logistic regression analysis revealed the factors affecting the use of traditional medical services. We selected covariates for the regression model considering the effects of demographic, socioeconomic, health behaviour and utilisation factors.

Finally, multiple linear regression analysis was performed to examine the effect of the uncovered service guarantee on the frequency of visits and cost of outpatient services in TKM. The regression coefficients were presented with the probability of significance. All statistical analyses were performed using SAS V.9.4, and the results were considered statistically significant when the $p$ value was less than 0.05 .

\section{RESULTS}

The prevalence of use of Korean traditional medicine (2009-2013) is shown in figures 2 and 3. The prevalence in the Western medicine group increased slightly, from $93.2 \%$ in 2009 to $93.9 \%$ in 2013 . On the other hand, the prevalence in the traditional medicine group decreased from $6.8 \%$ in 2009 to $6.1 \%$ in 2013. Approximately $6.1 \%$ (1874) of all doctor visits (30 982) were characterised as TKM services (online supplementary file 3 ).

Table 1 shows the groups using the Korean traditional medicine categorised according to treatment and prevention purposes. The general characteristics of the study population are also summarised in table 1. By sex, the rate of usage of therapeutic and preventive medical services was typically higher in women than in men. However, the percentage of male users using preventive 


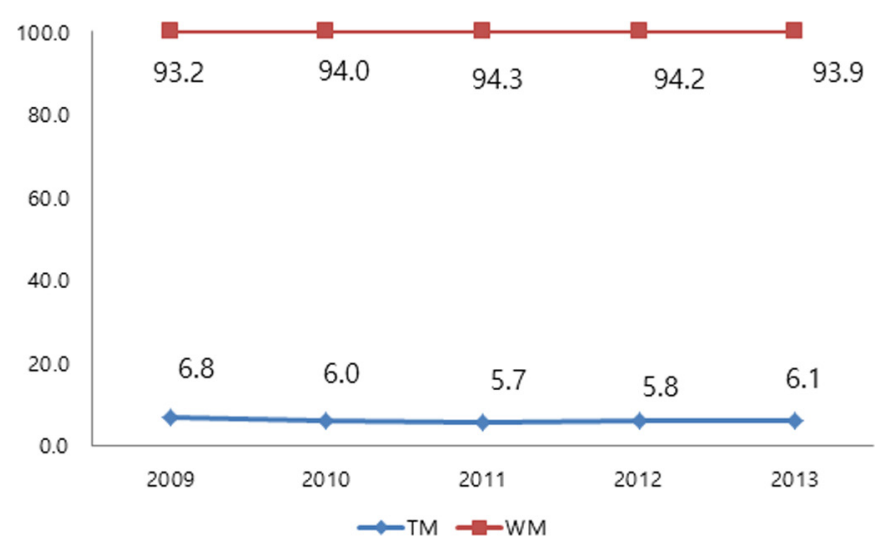

Figure 3 The trend of use of Korean traditional medicine (2009-2013). TM, traditional medicine; WM, Western medicine.

medical services was higher in 2010 (67.6\% vs $32.4 \%)$. By age, the rate of medical treatment service usage was highest in patients aged 50-59 years, while the highest rate of preventive medical service usage was in the 40-49 years age group. In 2013, individuals aged 20-29 years old demonstrated the highest rate of preventive medical service usage $(40.0 \%)$. By marital status, the rate of usage of both therapeutic and preventive medical services was higher among married individuals than among those who were divorced or unmarried. Most users of therapeutic medical services were in Seoul, whereas most preventive medical service users were in the Kyongsang area. By income level (divided by quartile), the fourth group used both therapeutic and preventive medical services in an uneven manner. Overall, the group of health insurance subscribers who showed the highest economic activity used the services most frequently. However, there was no record of preventive medical service usage among lowincome medical care patients from 2009 to 2013. By education level, middle and high school graduates primarily used therapeutic medical services, whereas preventive medical services were primarily used by college graduates. Therapeutic medical services were used for chronic diseases in $63 \%$ of the cases; in contrast, $63 \%$ of preventive medical service users did not have chronic diseases. The therapeutic medical service group exhibited more musculoskeletal diseases, whereas the preventive medical service group reported more health visits and visits for special illnesses. Health behaviour-related factors were similar throughout the duration of the study (20092013). In both medical service groups, the percentage of never-smokers was $>65 \%$, the percentage of high alcohol consumers was $>70 \%$, the irregular exercising group was approximately $70 \%$, and the normal weight group was $>70 \%$. These were similar over the duration of the study years. The rate of frequent visits to hospitals in the therapeutic medical service group in 2009 was $30 \%$, whereas it was $25 \%$ in the preventive medical service group. These distributions were similar in 2013. In 2012, both groups showed fairly low rates of frequent hospital visit usage, at $16 \%$ each (table 1 ).
The number of outpatients using TKM decreased by $18.6 \%$ over the 5-year study period, from 436 in 2009 to 355 in 2013; the number sharply decreased in 2011 after reduction of coverage. The ratio of outpatient medical service usage in Korea for therapeutic to preventive purposes was 9:1. Both therapeutic and preventive medical service usage decreased rapidly in 2011 after reduction of coverage. Usage later increased for therapeutic medical services, but continued to decrease for preventive medical services. The average number of outpatient visits for therapeutic purposes increased steadily from 19.6 in 2009 to 27.8 in 2013, while visits for preventive medical services decreased from 7.0 in 2009 to 4.1 in 2012, then rose again in 2013. The average out-of-pocket medical expenditure for therapeutic medical services steadily decreased from 42.07 in 2010 to 24.90 in 2013, while the expenditure for preventive medical services increased in 2010 and 2011, and only decreased from $\$ 226.86$ in 2011 to $\$ 151.71$ in 2012 , before increasing to $\$ 277.15$ in 2013. Considering the degree of coverage, the out-of-pocket cost of therapeutic services increased from $\$ 2.54$ in 2010 to $\$ 16.54$ in 2013, whereas the corresponding costs for preventive measures increased from $\$ 215.94$ in 2010 to $\$ 220.56$ in 2013. There were five types of treatments available for outpatient use among privately insured persons: acupuncture/moxibustion/subjugation, coagulation/sedative/ herbal medicine, hand therapy, physical therapy and other services. The most commonly used treatments were acupuncture/moxibustion/cupping, followed by herbal decoction and supplementary medicine, and physical therapy. The preventive measures most commonly used were medical herbs in package, followed by acupuncture/moxibustion/cupping and physical therapy. Therapeutic use of acupuncture/moxibustion/cupping decreased from 2009 to 2012, but has increased since 2013. The frequency of physical therapy treatment was low. There were 31 cases of preventive medicine (herbal decoction and supplementary medicine usage), but none after 2011. Hand therapy and other services were used less frequently (table 2 ). A logistic regression analysing the factors affecting the selection of TKM services among PHI subscribers is shown in online supplementary file 4 . The demographic and socioeconomic factors that significantly affected the use of TKM included sex, age, region, income, chronic diseases and number of outpatient visits $(\mathrm{p}<0.005)$.

To investigate the factors affecting outpatient visits for TKM, multiple linear regression analysis was performed according to the purpose of the visit. The fitness of the model (adjusted R-squared) was $38.4 \%$ for therapeutic services and $53.8 \%$ for preventive services (table 3 ). Therapeutic TKM visits increased despite not being guaranteed in PHI (coefficient=3.0, $\mathrm{p}=0.045$ ). With regard to sex, women used more therapeutic TKM services than men (coefficient $=2.8, \mathrm{p}<0.001$ ). Patients aged $70-79$ years were more likely to use TKM procedures than patients aged 20-29years (coefficient $=11.5, \mathrm{p}=0.012$ ). For preventive services, sex and age were not statistically significant. 


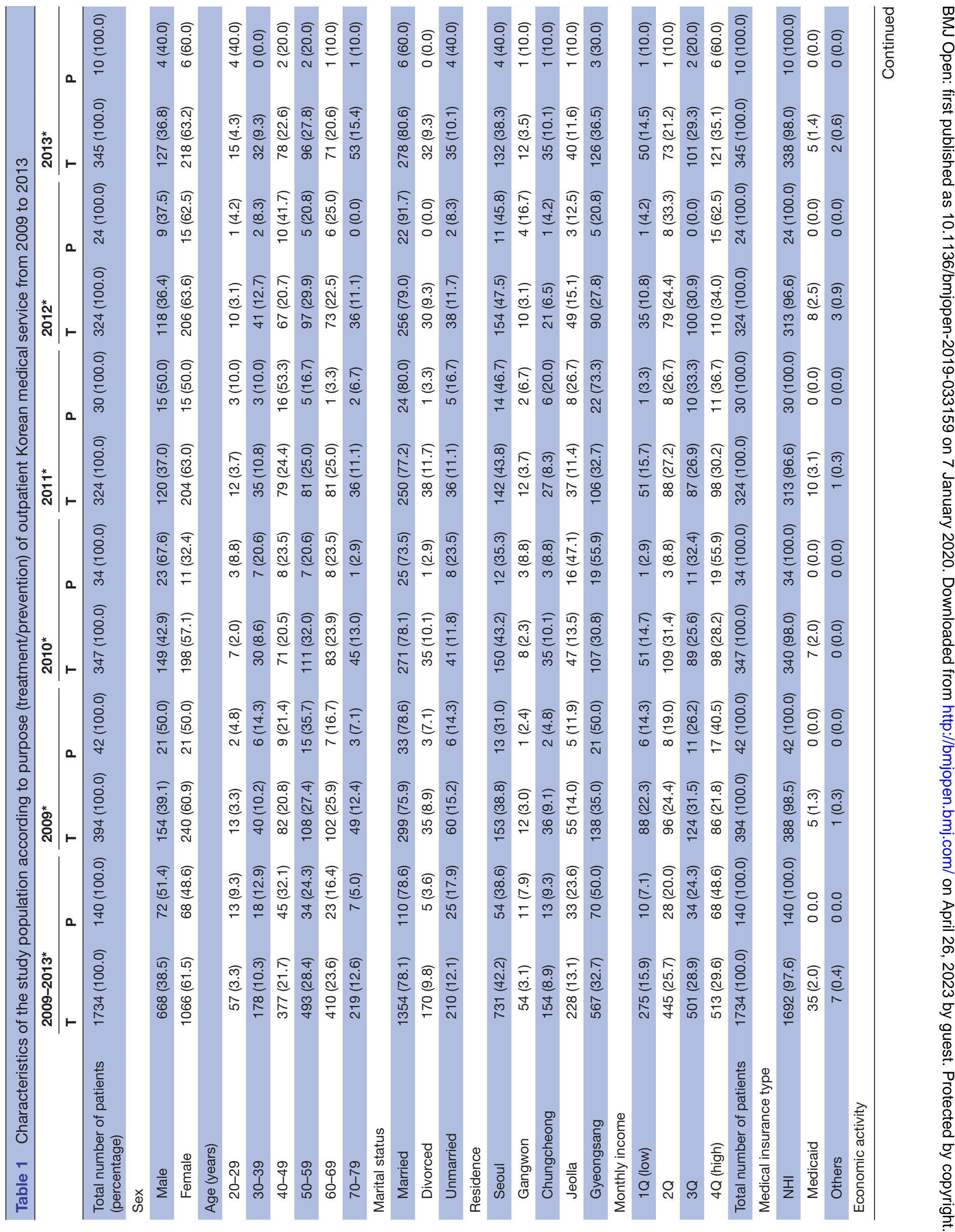




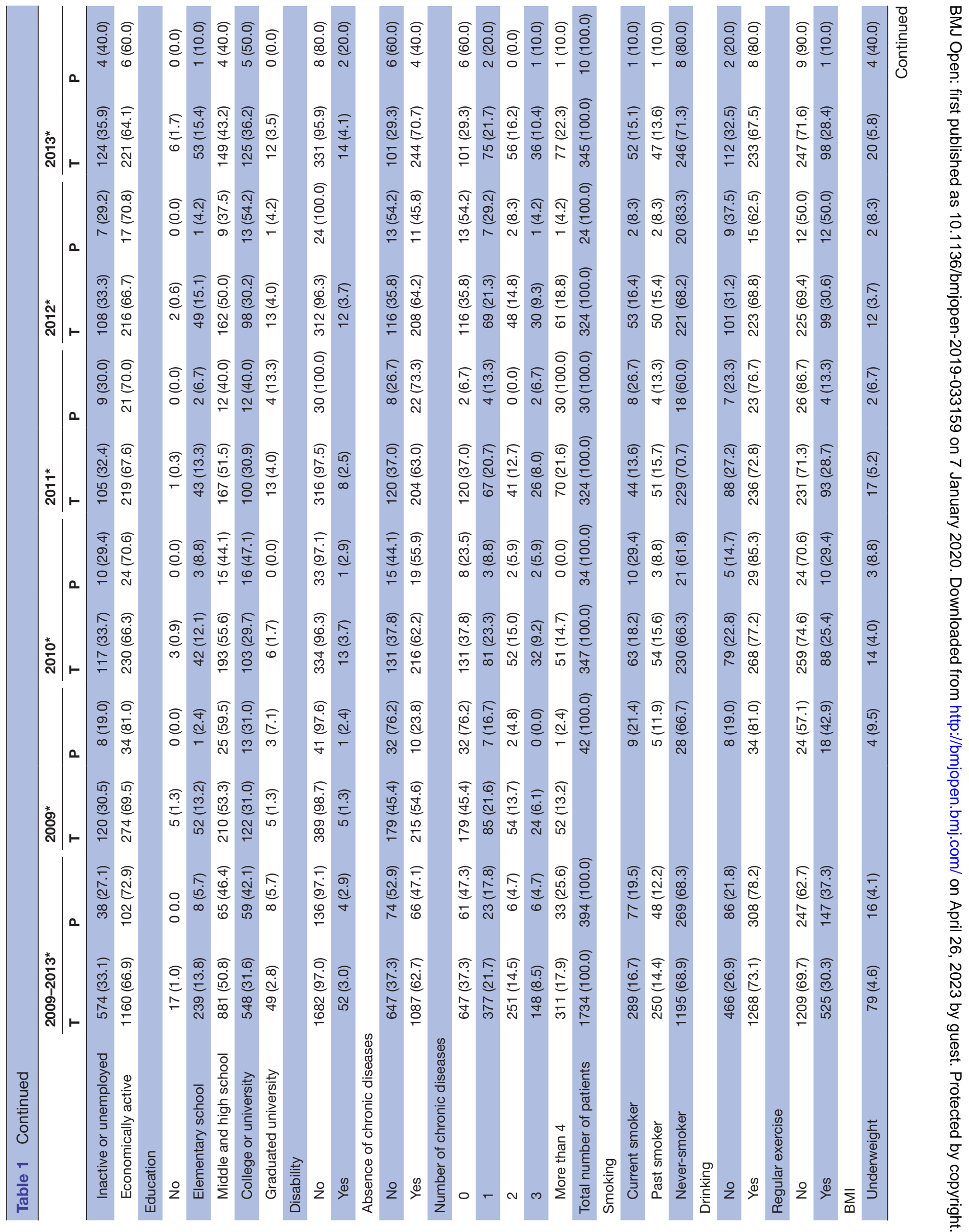




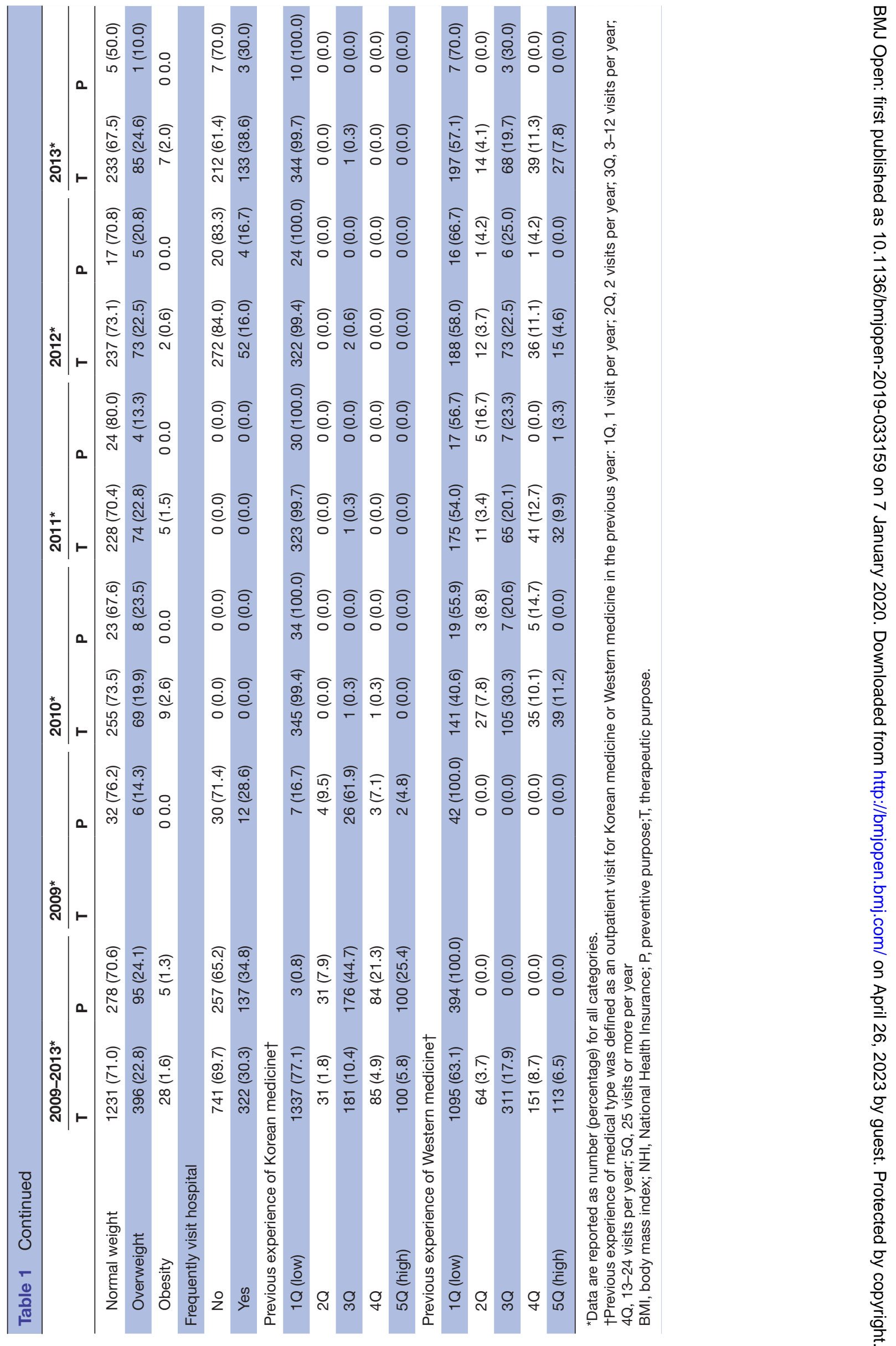




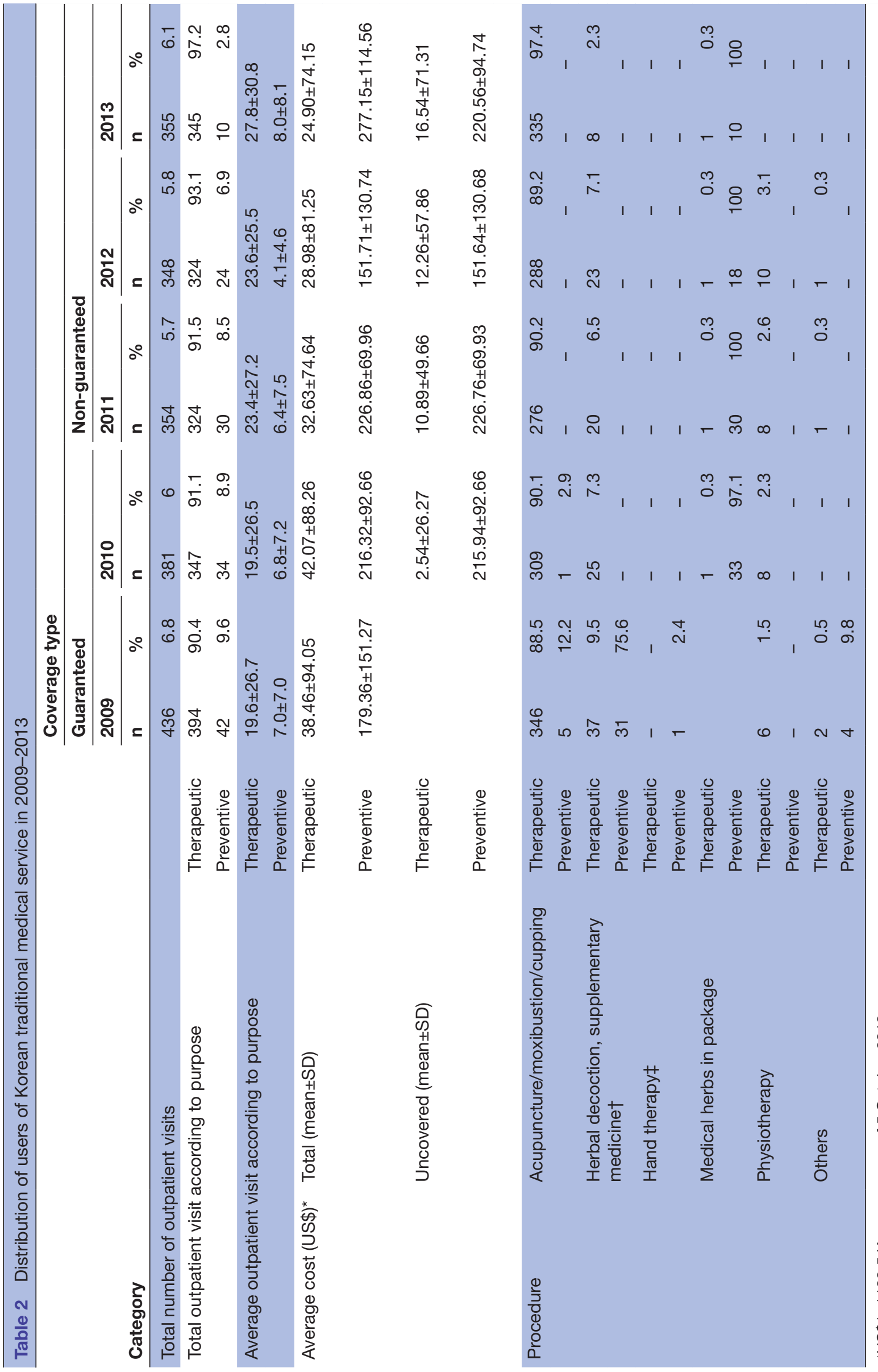


Table 3 Factors affecting the number of outpatient visits in
traditional Korean medicine

\begin{tabular}{|c|c|c|c|c|}
\hline \multirow[b]{2}{*}{ Category } & \multicolumn{2}{|l|}{ Therapeutic } & \multicolumn{2}{|l|}{ Preventive } \\
\hline & Coefficient & $P$ value & Coefficient & $P$ value \\
\hline \multicolumn{5}{|l|}{ Coverage type } \\
\hline \multicolumn{5}{|l|}{ Guaranteed } \\
\hline $\begin{array}{l}\text { Non- } \\
\text { guaranteed }\end{array}$ & 3.0 & $0.045^{\star}$ & -0.1 & 0.938 \\
\hline
\end{tabular}

Sex

\begin{tabular}{|c|c|c|c|c|}
\hline \multicolumn{5}{|l|}{ Male } \\
\hline Female & 2.8 & $<0.001^{*}$ & 1.1 & 0.446 \\
\hline \multicolumn{5}{|l|}{ Age (years) } \\
\hline \multicolumn{5}{|l|}{$20-29$} \\
\hline $30-39$ & -0.9 & 0.796 & 2.3 & 0.364 \\
\hline $40-49$ & -1.4 & 0.742 & 1.1 & 0.707 \\
\hline $50-59$ & -0.7 & 0.877 & 2.6 & 0.404 \\
\hline $60-69$ & 0.8 & 0.860 & -1.2 & 0.727 \\
\hline $70-79$ & 11.5 & $0.012^{\star}$ & -0.9 & 0.835 \\
\hline \multicolumn{5}{|l|}{ Marital status } \\
\hline \multicolumn{5}{|l|}{ Married } \\
\hline Divorced & 1.8 & 0.512 & 1.8 & 0.397 \\
\hline Unmarried & -3.5 & 0.315 & 1.0 & 0.816 \\
\hline \multicolumn{5}{|c|}{ Economic activity } \\
\hline \multicolumn{5}{|l|}{$\begin{array}{l}\text { Inactive or } \\
\text { unemployed }\end{array}$} \\
\hline $\begin{array}{l}\text { Economically } \\
\text { active }\end{array}$ & 2.1 & 0.117 & 0.7 & 0.635 \\
\hline \multicolumn{5}{|l|}{ Residence } \\
\hline \multicolumn{5}{|l|}{ Seoul } \\
\hline Gangwon & 1.8 & 0.587 & 2.0 & 0.402 \\
\hline Chungcheong & -0.6 & 0.781 & 1.5 & 0.536 \\
\hline Jeolla & -1.6 & 0.381 & -0.2 & 0.893 \\
\hline Gyeongsang & -0.8 & 0.521 & 1.0 & 0.359 \\
\hline \multicolumn{5}{|l|}{ Monthly income } \\
\hline \multicolumn{5}{|l|}{$1 \mathrm{Q}$ (low) } \\
\hline $2 \mathrm{Q}$ & 2.9 & 0.152 & -5.8 & $0.021^{*}$ \\
\hline $3 Q$ & 3.3 & 0.104 & -5.3 & $0.036^{*}$ \\
\hline 4Q (high) & 3.5 & 0.094 & -4.6 & 0.060 \\
\hline \multicolumn{5}{|l|}{ Private cost } \\
\hline \multicolumn{5}{|l|}{$1 \mathrm{Q}$ (low) } \\
\hline $2 Q$ & -1.0 & 0.520 & -2.5 & 0.106 \\
\hline $3 Q$ & -1.0 & 0.548 & -4.4 & $0.005^{*}$ \\
\hline 4Q (high) & 0.3 & 0.847 & -2.7 & 0.063 \\
\hline \multicolumn{5}{|l|}{ Smoking } \\
\hline \multicolumn{5}{|l|}{ Current smoker } \\
\hline Past smoker & 2.6 & 0.216 & 1.4 & 0.370 \\
\hline Never-smoker & 0.4 & 0.849 & 2.2 & 0.293 \\
\hline \multicolumn{5}{|l|}{ Drinking } \\
\hline \multicolumn{5}{|l|}{ No } \\
\hline Yes & 3.4 & $0.014^{*}$ & 2.7 & $0.048^{*}$ \\
\hline
\end{tabular}

Table 3 Continued

\begin{tabular}{|c|c|c|c|c|}
\hline \multirow[b]{2}{*}{ Category } & \multicolumn{2}{|l|}{ Therapeutic } & \multirow{2}{*}{$\begin{array}{l}\text { Preventive } \\
\text { Coefficient }\end{array}$} & \multirow[b]{2}{*}{$P$ value } \\
\hline & Coefficient & $P$ value & & \\
\hline \multicolumn{5}{|c|}{ Regular exercise } \\
\hline \multicolumn{5}{|l|}{ No } \\
\hline Yes & 0.2 & 0.860 & 1.1 & 0.357 \\
\hline \multicolumn{5}{|c|}{ Frequently visit hospital } \\
\hline \multicolumn{5}{|l|}{ No } \\
\hline Yes & 4.6 & $0.002^{*}$ & 3.1 & $0.041^{*}$ \\
\hline \multicolumn{5}{|c|}{$\begin{array}{l}\text { Number of } \\
\text { chronic diseases }\end{array}$} \\
\hline \multicolumn{5}{|l|}{0} \\
\hline 1 & 4.1 & 0.009 & 0.8 & 0.574 \\
\hline 2 & 5.8 & $0.002^{*}$ & 1.2 & 0.540 \\
\hline 3 & 9.5 & $<0.001^{*}$ & 6.1 & 0.074 \\
\hline More than 4 & 19.7 & $<0.001$ & 4.3 & $<0.001^{*}$ \\
\hline \multicolumn{5}{|c|}{ Previous experience of Korean medicine $†$} \\
\hline \multicolumn{5}{|l|}{ 1Q (low) } \\
\hline $2 Q$ & -8.8 & $0.030^{*}$ & -2.6 & 0.367 \\
\hline $3 Q$ & -6.5 & $0.004^{*}$ & 0.7 & 0.658 \\
\hline $4 Q$ & -1.1 & 0.702 & 9.4 & $0.002^{*}$ \\
\hline $5 \mathrm{Q}$ (high) & 18.3 & $<0.001^{*}$ & 16.9 & $<0.001^{*}$ \\
\hline \multicolumn{5}{|c|}{ Previous experience of Western medicine† } \\
\hline \multicolumn{5}{|l|}{ 1Q (low) } \\
\hline $2 \mathrm{Q}$ & -4.4 & 0.121 & 1.1 & 0.582 \\
\hline $3 Q$ & -2.2 & 0.197 & 2.8 & 0.060 \\
\hline $4 Q$ & 2.0 & 0.337 & 6.4 & 0.384 \\
\hline $5 \mathrm{Q}$ (high) & 17.8 & $<0.001^{*}$ & 13.4 & $<0.001^{*}$ \\
\hline $\begin{array}{l}\text { Adjusted R- } \\
\text { squared }\end{array}$ & 38.4 & & 53.8 & \\
\hline
\end{tabular}

Multiple linear regression analysis was performed by adjusting for covariates.

${ }^{*} \mathrm{P}<0.05$.

†Previous experience of medical type was defined as an outpatient visit for Korean medicine or Western medicine in the previous year: $1 \mathrm{Q}, 1$ visit per year; $2 \mathrm{Q}, 2$ visits per year; $3 \mathrm{Q}, 3-12$ visits per year; $4 \mathrm{Q}$, $13-24$ visits per year; $5 Q, 25$ visits or more per year.

However, monthly income (3Q) reduced TKM service usage (coefficient $=-5.3, p=0.036$ ). Finally, regardless of the purpose of visit, alcohol drinkers used TKM services more frequently than non-drinkers, and people who frequently visited a hospital also used more TKM services (coefficient $=4.6, \mathrm{p}=0.002$; coefficient $=3.1, \mathrm{p}=0.041)$. Also, regardless of the purpose of the visit, the more chronic diseases, the more people who have previously experienced TKM service use more TKM service $(p<0.001)$.

The results of the multiple linear regression analysis of factors affecting outpatient costs in TKM services were as follows. The fitness of the model (adjusted R-squared) was $26.1 \%$ for therapeutic purposes and $47.9 \%$ for preventive purposes (table 4). Without guarantee, therapeutic TKM outpatient cost decreased (coefficient $=-0.3, \mathrm{p}=0.001$ ). 
Table 4 Factors affecting outpatient costs in traditional Korean medicine

\begin{tabular}{|c|c|c|c|c|}
\hline \multirow[b]{2}{*}{ Category } & \multicolumn{2}{|l|}{ Therapeutic } & \multicolumn{2}{|l|}{ Preventive } \\
\hline & Coefficient & $P$ value & Coefficient & $\begin{array}{l}P \\
\text { value }\end{array}$ \\
\hline \multicolumn{5}{|l|}{ Coverage type } \\
\hline \multicolumn{5}{|l|}{ Guaranteed } \\
\hline Non-guaranteed & -0.3 & $0.001^{*}$ & 0.2 & 0.587 \\
\hline \multicolumn{5}{|l|}{ Sex } \\
\hline \multicolumn{5}{|l|}{ Male } \\
\hline Female & -0.1 & 0.432 & -0.5 & 0.232 \\
\hline \multicolumn{5}{|l|}{ Age (years) } \\
\hline \multicolumn{5}{|l|}{$20-29$} \\
\hline 30-39 & 0.1 & 0.560 & 0.1 & 0.921 \\
\hline $40-49$ & 0.1 & 0.840 & -0.9 & 0.240 \\
\hline $50-59$ & -0.3 & 0.295 & -0.5 & 0.510 \\
\hline $60-69$ & -0.2 & 0.462 & -0.6 & 0.517 \\
\hline $70-79$ & -1.0 & $<0.001^{*}$ & -0.2 & 0.836 \\
\hline \multicolumn{5}{|l|}{ Marital status } \\
\hline \multicolumn{5}{|l|}{ Married } \\
\hline Divorced & -0.1 & 0.421 & 0.0 & 0.954 \\
\hline Unmarried & 0.2 & 0.512 & -0.1 & 0.932 \\
\hline \multicolumn{5}{|l|}{ Economic activity } \\
\hline \multicolumn{5}{|c|}{ Inactive or unemployed } \\
\hline $\begin{array}{l}\text { Economically } \\
\text { active }\end{array}$ & 0.1 & 0.150 & 0.6 & 0.127 \\
\hline \multicolumn{5}{|l|}{ Residence } \\
\hline \multicolumn{5}{|l|}{ Seoul } \\
\hline Gangwon & -0.2 & 0.458 & 0.2 & 0.722 \\
\hline Chungcheong & -0.2 & 0.145 & -0.1 & 0.930 \\
\hline Jeolla & 0.0 & 0.991 & -0.0 & 0.935 \\
\hline Gyeongsang & -0.2 & $0.046^{*}$ & -0.2 & 0.432 \\
\hline \multicolumn{5}{|l|}{ Monthly income } \\
\hline \multicolumn{5}{|l|}{$1 \mathrm{Q}$ (low) } \\
\hline $2 Q$ & 0.4 & $0.006^{*}$ & 1.1 & 0.090 \\
\hline $3 Q$ & 0.4 & $0.005^{*}$ & 1.6 & $0.018^{*}$ \\
\hline 4Q (high) & 0.8 & $<0.001^{*}$ & 1.1 & 0.072 \\
\hline \multicolumn{5}{|l|}{ Private cost } \\
\hline \multicolumn{5}{|l|}{$1 Q$ (low) } \\
\hline $2 Q$ & 0.1 & 0.239 & -0.8 & $0.053^{*}$ \\
\hline $3 Q$ & 0.0 & 0.859 & -0.2 & 0.679 \\
\hline 4Q (high) & 0.1 & 0.621 & 0.2 & 0.665 \\
\hline \multicolumn{5}{|l|}{ Smoking } \\
\hline \multicolumn{5}{|l|}{ Current smoker } \\
\hline Past smoker & -0.2 & 0.096 & 0.1 & 0.800 \\
\hline Never-smoker & 0.0 & 0.891 & -0.8 & 0.129 \\
\hline \multicolumn{5}{|l|}{ Drinking } \\
\hline \multicolumn{5}{|l|}{ No } \\
\hline Yes & 0.0 & 0.588 & -0.1 & 0.702 \\
\hline
\end{tabular}

Continued
Table 4 Continued

\begin{tabular}{|c|c|c|c|c|}
\hline \multirow[b]{2}{*}{ Category } & \multicolumn{2}{|l|}{ Therapeutic } & \multicolumn{2}{|l|}{ Preventive } \\
\hline & Coefficient & $P$ value & Coefficient & $\begin{array}{l}P \\
\text { value }\end{array}$ \\
\hline \multicolumn{5}{|l|}{ No } \\
\hline Yes & 0.1 & 0.337 & 0.3 & 0.306 \\
\hline \multicolumn{5}{|c|}{ Frequently visit hospital } \\
\hline \multicolumn{5}{|l|}{ No } \\
\hline Yes & 0.1 & 0.580 & 0.6 & 0.118 \\
\hline \multicolumn{5}{|c|}{ Number of chronic diseases } \\
\hline \multicolumn{5}{|c|}{0} \\
\hline 1 & 0.1 & 0.556 & 0.5 & 0.176 \\
\hline 2 & 0.1 & 0.511 & 0.6 & 0.264 \\
\hline 3 & 0.0 & 0.775 & 0.9 & 0.305 \\
\hline More than 4 & 0.2 & 0.147 & 0.6 & 0.332 \\
\hline
\end{tabular}

Previous experience of Korean medicine†

$\begin{array}{lrrrr}1 Q \text { (low) } & & & & \\ 2 Q & 0.4 & 0.102 & -1.4 & 0.057^{*} \\ 3 Q & -0.2 & 0.159 & -0.8 & 0.049^{*} \\ 4 Q & -0.1 & 0.556 & 0.4 & 0.585 \\ 5 Q \text { (high) } & \mathbf{0 . 4} & \mathbf{0 . 0 2 2 *} & -1.5 & 0.168\end{array}$

Previous experience of Western medicine $\dagger$

\begin{tabular}{|rrrrr}
\hline $\mathrm{Q}$ (low) & & & & \\
\hline $\mathrm{Q}$ & 0.0 & 0.878 & -0.8 & 0.104 \\
$3 \mathrm{Q}$ & 0.0 & 0.734 & -0.2 & 0.601 \\
\hline $\mathrm{Q}$ & -0.2 & 0.289 & -0.2 & 0.748 \\
\hline $5 \mathrm{Q}$ (high) & 0.3 & $0.048^{*}$ & 1.4 & 0.448 \\
\hline Adjusted R-squared & 26.1 & & 47.9 & \\
\hline
\end{tabular}

Multiple linear regression analysis was performed by adjusting for covariates. A log conversion was performed for outpatient costs. ${ }^{*} \mathrm{P}<0.05$.

†Previous experience of medical type was defined as an outpatient visit for Korean medicine or Western medicine in the previous year: $1 Q, 1$ visit per year; $2 Q, 2$ visits per year; $3 Q, 3-12$ visits per year; $4 Q$, 13-24 visits per year; $5 Q, 25$ visits or more per year.

Patients aged 70-70 spent less on TKM outpatient services than patients aged 20-29years (coefficient $=-0.1$, $\mathrm{p}=0.001$ ). The higher the income, the higher TKM outpatient costs spent for therapeutic services (coefficient $=0.8$, $\mathrm{p}<0.001)$. However, for preventive services, sex and age were not statistically significant factors. Patients in the third quartile for income spent more on preventive TKM services compared with those in the first quartile (coefficient $=1.6, \mathrm{p}=0.018$ ).

\section{DISCUSSION}

The purposes of this study were to examine TKM outpatient visits and medical cost based on the guarantee of private insurance, and to analyse the demographic and social characteristics of TKM users with private insurance. Our results are consistent with the general view in 
the literature with regard to the demographic and social characteristics of patients using TKM.

First, women used TKM more than men, ${ }^{19-21}$ and they also had higher rate of usage of Western medical service compared with men. ${ }^{22}$ Women may use healthcare more often because they have longer life expectancy, higher anxiety regarding health and a tendency to actively manage healthcare as the primary caregivers of the family. ${ }^{23}$ Some scholars argue that women, especially middle-aged women, tend to use all possible means to deal with disease treatment and healthcare. ${ }^{24}$ Although women's utilisation rate of TKM is high, further studies are necessary to clearly ascertain the causative reasons.

Second, older groups use more therapeutic TKM services than younger groups. The high demand for traditional medicine found among women in this study is consistent with findings reported in domestic and foreign literature. However, the high demand among the elderly is somewhat contradictory to the literature. The majority of studies showed a high demand for TKM in the elderly. ${ }^{21} 23$ However, some studies show a higher demand for TKM in younger age groups ${ }^{25}$ and a higher demand overall regardless of age. ${ }^{26}$ With the increasing interest in lifestyle and health promotion ${ }^{27}$ and improvements in the scientific basis for treatment by traditional medicine, ${ }^{28}$ positive awareness of the usefulness of TKM has increased. ${ }^{29} 30$ Morris and Avorn ${ }^{31}$ argued that active publicity through mass media and the internet has influenced the preference of the younger generation for traditional medicine. Thus, it is necessary to develop and spread awareness of healthcare programmes that are compatible with younger generations of TKM users.

Third, higher income was correlated with higher utilisation rates of TKM. ${ }^{32}$ We found that the high-income group spent more on therapeutic and preventive TKM services than the low-income group. ${ }^{32}$ However, it is a reflection of Korean culture that a person with more economic resources spends less on preventive care than a person with less resources. In Korea, adults with economic resources often pay for traditional herbal medicine for their parents. Higher incomes often increase medical access due to better economic accessibility. Thus, wealthy people are more likely to buy PHI. ${ }^{33}{ }^{34}$ When PHI is complementary or supplementary, those who have the capacity to pay may also show higher tendency to purchase PHI. The results of previous studies show that high-income earners frequently use complementary medicine ${ }^{23}$ whereas low-income earners do not. ${ }^{35}$

We also compared outpatient visits and expenditures according to the purpose of the visit (therapeutic/ preventive) to evaluate the effect of the guarantee reduction policy. In this policy, private medical insurance subscribers using traditional medicine were excluded from guaranteed payment. Our results showed that when TKM users did not have guaranteed TKM treatment, the number of TKM visits for therapeutic purpose increased (coefficient=3.0, $\mathrm{p}=0.045$ ) compared with when they received guaranteed payment, and the TKM average cost decreased significantly (coefficient $=-0.3, p=0.001$ ). The increased number of outpatients who sought treatment for therapeutic purposes despite the PHI policy to reduce uncovered TKM services suggests a high need in Korea for TKM services for therapeutic purposes.

We also found that the average number of outpatient visits for therapeutic purposes increased steadily from 19.6 in 2009 to 27.8 in 2013, and the average outof-pocket medical expenditure for therapeutic TKM steadily decreased from $\$ 42.07$ in 2010 to $\$ 24.90$ in 2013. In particular, the fact that uncovered medical expenses increased from $\$ 2.54$ in 2010 to $\$ 10.89$ in $2011, \$ 12.26$ in 2012 and $\$ 16.54$ in 2013 also proves that uncovered TKM procedures continue to be for therapeutic purposes even after the guarantee reduction policy was enacted. Covered therapeutic TKM procedures such as acupuncture/moxibustion/cupping were found not to be influenced by the guarantee reduction policy. However, the utilisation of uncovered therapeutic TKM procedures such as herbal decoction/supplementary medicine/physiotherapy sharply declined due to this policy (table 2). Finally, the guarantee reduction policy had a positive impact on preventing the moral hazard of outpatient care expenditures for preventive purposes. This result is in accordance with previous studies. ${ }^{36}{ }^{37}$ Greater outpatient care expenditure by PHI purchasers implies that PHI has a fiscal spillover effect on the NHI. However, an increase in the number of outpatient visits and uncovered TKM medical expenses for therapeutic purposes is due to the public's need for TKM procedures that are uncovered. The relatively high level of uncovered TKM services suggests a need for a PHI system that complements the cost-sharing burden of public systems to improve TKM access. Therefore, our findings suggest that policy makers should extend the scope of PHI coverage to those therapeutic TKM services that are uncovered, have high public demand and that have been proven effective. Although Korea has an NHI system with universal coverage for the population, more than $80 \%$ of the population aged 20-64years have supplementary PHI. ${ }^{38}$ Many Koreans buy private insurance due to a cultural influence that promotes being prepared for a 'rainy day', as the financial protection provided by NHI is not adequate. Koreans are 1.8 times more likely to self-pay for medical expenses than the OECD average. ${ }^{39}$ The direct burden ratio in Korean households is as high as $36.8 \%$. In other countries with healthcare systems similar to Korea, the direct burden ratio was $6.8 \%, 12.3 \%, 12.5 \%$ and $12.1 \%$ in France, the Netherlands, Germany and Japan, respectively. ${ }^{39}$ Although the Korean government has pursued a policy of enhancing public insurance to reduce the burden on Koreans in order to strengthen NHI coverage, there has been limited improvement in the rate of health insurance coverage, which the public perceives as a failure to manage the uncovered portion.

Further, the economic burden associated with the use of TKM is a current problem in Korea. ${ }^{40}$ Although some medical treatments, such as acupuncture and 
moxibustion, are covered by NHI, the coverage is limited in most cases. ${ }^{741}$ In particular, the burden ratio of uncovered services is $18.4 \%$ for Korean Western clinics and $30.7 \%$ for Korean traditional clinics. ${ }^{42}$ Thus, there is an unmet medical need that Korean people cannot fulfil even if they wished to. ${ }^{21}$ Fortunately, from March 2019, a typical TKM procedure known as Chuna therapy will be included in the NHI coverage, and thus the economic burden associated with the use of TKM will be reduced. Improving economic access to TKM services may help improve the quality of life of the Korean population. If PHI is well managed to meet the needs and preferences of the public, it can be a useful tool to supplement existing health financing options. ${ }^{43}$ Therefore, it is necessary for Korean policy makers to inject public funds into the expansion of NHI benefits for TKM as well as into the development of private insurance products. Further, Korean standardised guidelines need to be updated for uncovered TKM for private medical insurance.

This study has limitations. First, the results cannot be generalised outside of Korea because the cultural background and reimbursement systems of other countries are different. In order to compare these findings with the results of research studies from other countries, the results should be interpreted considering the cultural background and preferences for complementary medicine. Our results may be misleading if some facts related to healthcare delivery systems and health-related policies that affect the use of TKM are not considered. Second, this study focused on the utilisation of outpatient services among consumers and could not control for the effects of other factors due to lack of variables. As healthcare providers make recommendations to patients and can decide on the degree of care in Korea, taking into account their private insurance status, ${ }^{44}$ future studies on the impact of PHI must consider provider behaviour. In addition to demographic factors, health problem (history of diseases such as stroke, mental disorders, heart disease, chronic obstructive pulmonary disease, liver cirrhosis, kidney disease, diabetes, hypertension, hyperlipidaemia), distance to medical institutions and potential moral hazard due to health insurance can affect healthcare usage in Korea. ${ }^{45}$ Third, One limitation of this study is the possibility of recall bias because the data were collected patient questionnaires, rather than medical records. In the case of TKM services, the number of samples was small, which may indicate bias in the selection of subjects. Finally, this study was conducted over a short period (2009-2013), and further analyses will be able to adjust for selection effects using accumulated longitudinal data. ${ }^{46}$

Despite these limitations, our study has several strengths. This study analysed the current state of TKM services of privately insured persons based on the KHPS data. In particular, the KHPS data used in this study were collected using self-reported questionnaires and included uncovered service costs. Therefore, utilisation of TKM services, a high proportion of which are uncovered, could be accurately assessed. Previous studies excluded healthcare visits or expenditures related to beauty or cosmetics, plastic surgery, dental care, traditional medical care, community public health centres, long-term care hospitals, and midwifery services because these services are usually not guaranteed by PHI. Therefore, there are very few studies available to understand the various patterns of consumption behaviours as well as supply patterns of private healthcare services for PHI subscribers.

Finally, while the results of previous studies have been used to assess and develop health policies, there is a lack of data on patterns of TKM services. Although comparable studies were conducted a few decades ago, they are limited to a single year or disease range. ${ }^{19-21} 2325293032$ This study is unique in that it compares usage of services including uncovered services by privately insured persons in Korea. We believe that the current study would serve as a useful reference for other countries, ${ }^{47}$ such as France, Germany, Japan and Ireland, ${ }^{5}$ where large proportions of the population have PHI that complement public system coverage by cost-sharing. Based on open-source national survey data of the whole population of Korea, this study offers meaningful results that evaluate and can help direct the current policy for reducing the uncovered TKM guarantee of private insurance.

\section{CONCLUSIONS}

In summary, we found that the increased number of TKM outpatient visits and uncovered expenses for therapeutic purposes, which resulted from the policy excluding uncovered TKM services from PHI, can be interpreted as the Korean population's need for covered TKM services. Because the uncovered proportion of TKM services is relatively high, it is necessary for the PHI system to have a complementary cost-sharing role with the NHI to enhance access to TKM. Policy makers consider policies that are adapted to a country's institutional capacities and standards and PHI can operate efficiently. Ultimately, by improving economic access to TKM services, the population's quality of life can be improved.

Contributors BJ constructed the study design and analysed the data. BJ and JK interpreted the results. JK and I-HH were the scientific advisors. BJ guided and directed this study, and drafted the original manuscript. JK was the statistical investigator. JL and I-HH critically revised the draft. All authors have read and approved the final manuscript.

Funding The authors have not declared a specific grant for this research from any funding agency in the public, commercial or not-for-profit sectors.

Competing interests None declared.

Patient consent for publication Not required.

Ethics approval This study was approved by the Institutional Review Board of Jaseng Hospital of Korean Medicine in Seoul, Korea (JASENG 2019-11-002), with a waiver for informed consent because the data were obtained from a public database (https://www.khp.re.kr:444/eng/data/data.do).

Provenance and peer review Not commissioned; externally peer reviewed.

Data availability statement Data are available upon reasonable request. The data sets generated and/or analysed during the study are available in the KHPS repository. The KHPS data are third-party data not owned by the authors. The KHPS data are available on visit or by mail on direct, email or fax submission of the data 
set request form and declaration of data use, which is downloadable from the 'KHPS' website (https://www.khp.re.kr:444/eng/data/data.do) for free.

Open access This is an open access article distributed in accordance with the Creative Commons Attribution Non Commercial (CC BY-NC 4.0) license, which permits others to distribute, remix, adapt, build upon this work non-commercially, and license their derivative works on different terms, provided the original work is properly cited, appropriate credit is given, any changes made indicated, and the use is non-commercial. See: http://creativecommons.org/licenses/by-nc/4.0/.

\section{ORCID iDs}

Boyoung Jung http://orcid.org/0000-0001-9812-0745

In-Hyuk Ha http://orcid.org/0000-0002-5020-6723

\section{REFERENCES}

1 World Health organization. World health statistics 2015. World Health organization, 2015.

2 Jones RS. Health-Care reform in Korea. Economics department working papers No. 797. OECD, 2010.

3 Health Insurance Review \& Assessment Service. Korean healthcare system: HIRA, 2018. Available: https://www.hira.or.kr/dummy.do? pgmid=HIRAJ010000006002 [Accessed 21 Feb 2018].

4 Medicine(NIKOM) NDIoK. NIKOM report of Korean medicine policy national development Institute of Korean medicine; 2016.

5 Robertson R, Gregory S, Jabbal J. The social care and health systems of nine countries. Commission on the future of health and social care in England: The King's Fund, 2014.

6 Lee T-H, Kim N-I, Maeng W-J. Changing definitions of complementary and alternative medicine and related research analysis in Korea. Korean J Oriental Med 2010;16.

7 Jung B, Bae S, Kim S. Use of Western medicine and traditional Korean medicine for joint disorders: a retrospective comparative analysis based on Korean nationwide insurance data. Evid Based Complement Alternat Med 2017;2017:2038095:1-31.

8 Lee SI, Khang YH, Lee MS, et al. Complementary and alternative medicine use in Korea: prevalence, pattern of use, and out-of-pocket expenditures. Korean J Prevent Med 1999;32:546-55.

9 Ock SM, Choi JY, Cha YS, et al. The use of complementary and alternative medicine in a general population in South Korea: results from a national survey in 2006. J Korean Med Sci 2009;24:1-6.

10 Chae H, Lee S, Park SH, et al. Development and validation of a personality assessment instrument for traditional Korean medicine: sasang personality questionnaire. Evid Based Complement Alternat Med 2012;2012:657013:1-12.

11 Roh GS, Seo S-W, Yeo S, et al. Efficacy of a traditional Korean medicine, Chung-Sang-Bo-Ha-Tang, in a murine model of chronic asthma. Int Immunopharmacol 2005;5:427-36.

12 Park J, Park H, Lee H, et al. Deqi sensation between the acupuncture-experienced and the naïve: a Korean study II. Am J Chin Med 2005;33:329-37.

$13 \mathrm{KHIDI}$. Survey on medical use of Korean traditional medicine and herbal medicine consumption; 2014.

14 Jung Y, Seo N, Go S. A report on the Korea health panel survey of 2008. 38. Seoul: Korea Institute for Health and Social Affairs, 2010.

15 Choi JH, Kang S, You CH, et al. The determinants of choosing traditional Korean medicine or conventional medicine: findings from the Korea health panel. Evid Based Complement Alternat Med 2015;2015:147408:1-9.

16 Cho Y. Issue: prerequisites for guarantee of Non-payment of medical insurance. KIRI Weekly issue 2013;230:1-10.

17 Diehr P, Yanez D, Ash A, et al. Methods for analyzing health care utilization and costs. Annu Rev Public Health 1999;20:125-44.

18 Barber J, Thompson S. Multiple regression of cost data: use of generalised linear models. J Health Serv Res Policy 2004;9:197-204.

19 Kim S-Y, Park J-Y. The utilization of Western and Oriental medica services by outpatients with musculoskeletal system disorders and its related factors. Korean J Health Serv Manage 2012;6:27-38.

20 Lee H-J, Yoo W-S, Chung S-K. Determining factors for the use of Oriental healthcare services for survey subjects with chronic illnesses: 2005 National health and nutrition examination survey. J Society Prevent Korean Med 2011;15

21 Park J-E, Kwon S-M. Determinants of the utilization of Oriental medical services by the elderly. J Korean Med 2011;32.

22 Brett KM, Burt CW. Utilization of ambulatory medical care by women: United States, 1997-98. Vital Health Stat 13 2001:1-46.

23 Conboy L, Patel S, Kaptchuk TJ, et al. Sociodemographic determinants of the utilization of specific types of complementary and alternative medicine: an analysis based on a nationally representative survey sample. J Altern Complement Med 2005;11:977-94.

24 Wade C, Chao M, Kronenberg F, et al. Medical pluralism among American women: results of a national survey. $J$ Womens Health 2008;17:829-40.

25 Boon H, Stewart M, Kennard MA, et al. Use of complementary/ alternative medicine by breast cancer survivors in Ontario: prevalence and perceptions. J Clin Oncol 2000;18:2515-21.

26 Astin JA. Why patients use alternative medicine: results of a national study. JAMA 1998;279:1548-53.

27 Chan JM, Elkin EP, Silva SJ, et al. Total and specific complementary and alternative medicine use in a large cohort of men with prostate cancer. Urology 2005;66:1223-8.

28 Ernst $\mathrm{E}$. The role of complementary and alternative medicine. BMJ 2000;321:1133-5.

29 Kim Y-H. A study on nursing students' attitudes toward complementary and alternative medicine (cam). J Korean Public Health Nurs 2004;18:276-85.

30 Woo J-M, Park E-J, Lee M, et al. Changes in attitudes toward and patterns in traditional Korean medicine among the general population in South Korea: a comparison between 2008 and 2011. BMC Complement Altern Med 2014;14:436.

31 Morris CA, Avorn J. Internet marketing of herbal products. JAMA 2003;290:1505-9.

32 Complementary and alternative medicine use among adults: United States, 2002. Seminars in integrative medicine 2004.

33 Riphahn RT, Wambach A, Million A. Incentive effects in the demand for health care: a bivariate panel count data estimation. J Appl Econ 2003;18:387-405.

34 Kiil A. What characterises the privately insured in universal health care systems? A review of the empirical evidence. Health Policy 2012;106:60-75.

35 Arcury TA, Grzywacz JG, Bell RA, et al. Herbal remedy use as health self-management among older adults. J Gerontol B Psychol Sci Soc Sci 2007;62:S142-9.

36 Jung K. An empirical study on the relationship between private health insurance and moral hazard. K Insurance $J$ 2006;75:1-25.

37 Manning WG, Newhouse JP, Duan N, et al. Health insurance and the demand for medical care: evidence from a randomized experiment. Am Eco Review 1987;77:251-77.

38 Jeon B, Kwon S. Effect of private health insurance on health care utilization in a universal public insurance system: a case of South Korea. Health Policy 2013;113:69-76.

39 OECD. OECD health data 2017, 2017. Available: http://www.oecd. org/els/health-systems/health-statistics.htm

40 Jeong WY. [The brief history of Korean traditional medicine (18991999)]. Uisahak 1999;8:169-86.

$41 \mathrm{Lim}$ B. Korean medicine coverage in the National health insurance in Korea: present situation and critical issues. Integr Med Res 2013;2:81-8.

42 Welfare $\mathrm{MoH}$. Standard clinical Guideline development for traditional medicine and health insurance coverage improvement, 2016.

43 Drechsler D, Jütting JP. Is there a role for private health insurance in developing countries?: DIW discussion papers, 2005.

44 Card D, Dobkin C, Maestas N. The impact of nearly universal insurance coverage on health care utilization: evidence from Medicare. Am Econ Rev 2008;98:2242-58.

$45 \mathrm{Kim}$ LS. The experience of the stroke patients about the use of Oriental medicine. J Korean Public Health Nurs 1997;11:82-92.

46 Bolhaar J, Lindeboom M, van der Klaauw B. A dynamic analysis of the demand for health insurance and health care. Eur Econ Rev 2012;56:669-90.

47 Colombo F, Tapay N. Private health insurance in OECD countries. OECD, 2004. 